\title{
Long term alcohol intake and risk of rheumatoid arthritis in women: a population based cohort study
}

\author{
(c) $(1) \Theta$ OPEN ACCESS
}

\author{
Daniela Di Giuseppe PhD student ${ }^{1}$, Lars Alfredsson professor ${ }^{2}$, Matteo Bottai professor ${ }^{3}$, Johan \\ Askling associate professor ${ }^{4}$, Alicja Wolk professor ${ }^{1}$
}

${ }^{1}$ Division of Nutritional Epidemiology, Institute of Environmental Medicine, Karolinska Institute, Box 210, 171 77, Stockholm, Sweden; ${ }^{2}$ Division of Cardiovascular Epidemiology, Institute of Environmental Medicine, Karolinska Institute; ${ }^{3}$ Division of Biostatistics, Institute of Environmental Medicine, Karolinska Institute; ${ }^{4}$ Clinical Epidemiology Unit, Department of Medicine, Karolinska Hospital, Stockholm

\begin{abstract}
Objective To analyse the association between alcohol intake and incidence of rheumatoid arthritis in women.

Design Prospective cohort study with repeated measurements.

Setting The Swedish Mammography Cohort, a population based cohort from central Sweden.

Participants 34141 women born between 1914 and 1948, followed up from 1 January 2003 to 31 December 2009.

Main outcome measures Newly diagnosed cases of rheumatoid arthritis identified by linkage with two Swedish national registers. Data on alcohol consumption were collected in 1987 and 1997.

Results During the follow-up period (226 032 person years), 197 incident cases of rheumatoid arthritis were identified. There was a statistically significant $37 \%$ decrease in risk of rheumatoid arthritis among women who drank $>4$ glasses of alcohol ( 1 glass $=15 \mathrm{~g}$ of ethanol) per week compared with women who drank $<1$ glass per week or who never drank alcohol (relative risk 0.63 (95\% confidence interval 0.42 to 0.96 ), $\mathrm{P}=0.04$ ). Drinking of all types of alcohol (beer, wine, and liquor) was non-significantly inversely associated with the risk of rheumatoid arthritis. Analysis of long term alcohol consumption showed that women who reported drinking $>3$ glasses of alcohol per week in both 1987 and 1997 had a $52 \%$ decreased risk of rheumatoid arthritis compared with those who never drank (relative risk 0.48 (0.24 to 0.98)).
\end{abstract}

Conclusion Moderate consumption of alcohol is associated with reduced risk of rheumatoid arthritis.

\section{Introduction}

Rheumatoid arthritis is an inflammatory autoimmune disease that primarily affects the joints. The prevalence of rheumatoid arthritis in the adult population is around $0.8 \%$, higher in women than in men. ${ }^{1}$ It is known that long term alcohol consumption may affect immune function and that alcohol may down regulate production of proinflammatory molecules. ${ }^{2-4}$

A significant inverse association between alcohol consumption and risk of rheumatoid arthritis in both men and women has been observed in case-control studies ${ }^{5-8}$ but not in cohort studies. ${ }^{9-11}$ Since case-control studies may be affected by differential recall bias, it is difficult to conclude whether alcohol is inversely associated with rheumatoid arthritis. Moreover, none of the case-control studies reported on the consumption of specific types of alcohol (beer, wine, or liquor). Thus, it is possible that the observed association could be influenced by other characteristics specific to a certain type of alcoholic drink. The aim of this study was to evaluate the association between long term alcohol consumption and incidence of rheumatoid arthritis in a population based, prospective, cohort study with specific reference to the dose-response relation and also to specific types of alcoholic drink.

\section{Methods \\ Study population}

The Swedish Mammography Cohort is a prospective cohort study established between 1987 and 1990 when all women born between 1914 and 1948 and living in Uppsala and Västmanland counties in central Sweden received a questionnaire by mail regarding alcohol consumption, diet, height, weight, parity, and educational level; 66651 returned the questionnaire (response rate $74 \%$ ). In the autumn of 1997 a second questionnaire was sent to the women still alive. The new questionnaire updated data from the first questionnaire and collected additional information regarding smoking history, physical activity, and use of dietary supplements. The response rate was $70 \%(\mathrm{n}=39$ 227). The cohort well represented the whole Swedish female 
population aged 48-83 years in 1997 in terms of age distribution, educational level, and prevalence of overweight.

For the analysis in this study, we excluded women with incorrect or missing personal identification numbers $(n=243,0.6 \%)$, and women who in the 1997 questionnaire reported extreme energy intake $(n=502,1.3 \%)$ or missing values on alcohol status $(n=440$, $1.1 \%$ ). We also excluded women who were diagnosed with rheumatoid arthritis (ICD-10 (international classification of diseases, 10th revision) codes M05 and M06) ( $\mathrm{n}=443,1.2 \%)$, or another non-rheumatoid arthritis joint condition (ICD-10 codes M07-M12, M14, M45, M46, M30-M36) (n=1899, 5.1\%), or who died $(\mathrm{n}=1559$, identified through the Swedish Death Register) after filling the second questionnaire and before the start of follow-up on 1 January 2003. The final study cohort included 34141 women aged 54-89 years at the start of follow-up.

\section{Assessment of alcohol and covariates}

Information about alcohol consumption was collected in 1987 and 1997 using a food frequency questionnaire. Data on beer, wine, and liquor consumption were collected with a question on how many times the participant had consumed each type of drink during the past year. There were eight pre-specified response categories ranging from never or seldom to more than three times a day. Information about amount of beer, wine, and liquor consumed on each occasion was also collected in 1997 with an open ended question. We calculated the average number of glasses of alcoholic beverage per week ( 1 standard glass = $15 \mathrm{~g}$ of alcohol, corresponding to approximately $500 \mathrm{~mL}$ of beer, $150 \mathrm{~mL}$ of wine, and $50 \mathrm{~mL}$ of liquor) combining information about frequency and amount of drinking. Partial non-response for alcohol drinking frequency ( $10.3 \%$ for beer, $3.9 \%$ for wine, and $12.1 \%$ for liquor) was assumed to mean none or seldom consumption. This assumption was based on a study performed in a Swedish population evaluating the "zero approach" to handle partial non-response, showing that $74.1 \%$ of missing answers for alcohol beverages corresponded to true non-consumption. ${ }^{12}$

The estimates of alcohol intake based on the food frequency questionnaire in 1997 had good validity compared with 14 interviews that measured 24-hour recall of intake with a correlation coefficient of $0.81 .^{13}$ The alcohol estimates based on the food frequency questionnaire in 1987 and used in long term analysis had a correlation coefficient of 0.9 in comparison with four one-week weighed diet records (three to four months apart). ${ }^{14}$

Information about smoking history was collected for status and average number of cigarettes smoked a day at different ages (15-20, 21-30, 31-40, 41-50, 51-60, and present year). Weight and height were self reported, and body mass index was calculated (weight $(\mathrm{kg}) /\left(\right.$ height $\left.(\mathrm{m})^{2}\right)$. Educational level was assessed with a five-item question (from six years of basic education to university studies).

\section{Identification of cases and follow-up of the cohort}

To identify cases of rheumatoid arthritis, we used three different Swedish registers: the Outpatient Register, the Swedish Rheumatology Register, and the Inpatient Register (used only for sensitivity analyses). Since 2001, the Outpatient Register of the National Board of Health and Welfare collects information on outpatient visits in non-primary care (such as visits to internists or rheumatologists). The Swedish Rheumatology Register is a clinical register established in the mid-1990s to follow incident rheumatoid arthritis cases longitudinally as part of standard care. The Inpatient Register of the National Board of Health and Welfare contains virtually complete information on all hospitalisations, starting in 1987. Chart reviews indicate that approximately $90 \%$ of the cases of rheumatoid arthritis identified in the register fulfil the American College of Rheumatology criteria. ${ }^{15} 16$

To identify participants with newly diagnosed rheumatoid arthritis during the follow-up period, we used the Outpatient Register and the Swedish Rheumatology Register.

The follow-up period started on 1 January 2003 and ended on 31 December 2009. To exclude prevalent cases, we introduced a two year lag period from 2001 (first year of data in the Outpatient Register) such that the study period for our main analysis started in 2003. This delay was based on the distribution of the annual number of new patients with rheumatoid arthritis identified in the Outpatient Register (which in 2001 contained a mix of prevalent and incident cases, see appendix on bmj.com). In sensitivity analyses, alternative lag periods were used and cases identified through hospitalisations were included (see appendix). Deaths occurring in the cohort were ascertained through the Swedish Death Register. For all linkages, we used the unique Swedish personal identification number as linkage key. ${ }^{17}$

\section{Statistical analysis}

We used the Cox proportional hazard model to estimate the association between alcohol intake and occurrence of rheumatoid arthritis in terms of relative risk, reported as hazard rate ratios and $95 \%$ confidence intervals, using SAS (version 9.2). P values $\leq 0.05$ were considered statistically significant. All relative risks had age as the time scale, ${ }^{18} 19$ and we calculated age at end of follow-up as age at death, first rheumatoid arthritis diagnosis, or 31 December 2009, whichever was earlier. We considered the following as potential confounders: age (time scale of the models), cigarette smoking status (categorised as never, former, current $\leq 10$ cigarettes/day, or current $>10$ cigarettes/day), body mass index (categorised by quartiles), educational level ( $<10$, $10-12,>12$ years, other), parity $(0,1,2$, or $>2$ children), menopausal status (yes or no), meat consumption (quartiles), and consumption of dairy products consumption (quartiles). However, in the final model only smoking status was included, since the inclusion of the other variables changed the estimated relative risks only marginally. We checked the assumption of hazard proportionality by regressing the scaled Schoenfeld's residual against survival time. ${ }^{20}$ No evidence of departure from the proportionality assumption was observed in the model. We tested for linear trend by using the median value of each exposure category.

Women were categorised according to alcohol status as never, former, occasional ( $\leq 2$ alcoholic drinks a week), or regular drinkers( $>2$ alcoholic drinks a week). We also analysed the association of risk of rheumatoid arthritis with number of glasses of alcohol consumed per week (categorised as $<1$ or never, 1-2, $2-4$, and $>4$ glasses a week) and with monthly frequency of beer, wine, and liquor consumption. Monthly frequencies for beer and liquor were categorised as never, $<1,1-4$, and $>4$ times, whereas frequency for wine was categorised as $<1,1-4,5-8$, and $>8$ times because of the different distribution of this beverage in the population. Relative risks for beer, wine, and liquor were mutually adjusted. We also analysed the long term effect of alcohol consumption by using information on alcohol intake from the 1987 questionnaire. 
We estimated the dose-response trend in the association between weekly alcohol intake and risk of rheumatoid arthritis using restricted cubic spline with knots at 1,2, 4, and 6 glasses per week. ${ }^{21}$ To implement restricted cubic splines we used Stata (version 11.1).

As indicated above, a series of sensitivity analyses were performed to evaluate the consistency of the results that were obtained in the main analysis. We first considered different outcome definitions by further delaying the start of the follow-up and adding newly diagnosed rheumatoid arthritis patients identified via hospitalisation data from the Inpatient Register (see appendix A on bmj.com). We then performed a probabilistic sensitivity analysis based on the assumption of presence among newly diagnosed cases of rheumatoid arthritis of 0 to $20 \%$ prevalent cases with different assumed drinking habits compared with incident cases (appendix B).

\section{Results}

During the seven years of follow-up (226 032 person years), 197 new cases of rheumatoid arthritis were registered. In the cohort, regular drinkers drank more wine (average 7.6 times/month) than beer (6.3 times/month) or liquor (2.1 times/month), and they were more likely to smoke compared with occasional drinkers (table $1 \Downarrow$ ). Former drinkers represented $4 \%$ of the cohort, and only six cases were among them. Never drinkers had the lowest prevalence of smoking. Those women who drank more than four glasses of alcohol a week were younger and were more likely to smoke compared with those who drank less. Among the women who developed rheumatoid arthritis, $105(53 \%)$ were occasional drinkers ( $\leq 2$ drinks a week), while $65(33 \%)$ were regular drinkers ( $>2$ drinks a week). The age standardised rate of rheumatoid arthritis was smaller among women who drank more than four glasses of alcohol a week (7 per 10000 person years) than among women who drank less than one glass a week (9.1 per 10000 person years).

There was a non-significant decrease in risk for never and former drinkers compared with occasional drinkers in the age adjusted model, but, after further adjustment for smoking, the risk of rheumatoid arthritis was 9\% larger for never drinkers and 19\% smaller for regular drinkers compared with occasional drinkers(table $2 \Downarrow$ ).

The age adjusted relative risk for women who drank more than four glasses of alcohol a week was 0.74 (95\% confidence interval 0.49 to 1.11 ) compared with women who drank less than one glass a week or never drank, but it was not statistically significant. After adjustment for smoking as well, the relative risk became significant with a $37 \%$ decrease in risk (relative risk 0.63 (0.42 to 0.96)).Further adjustment for body mass index, educational level, parity, menopausal status, and consumption of meat and dairy products indicated that the confounding of the estimated risk of the age adjusted model could be attributable to smoking, since the multivariable adjusted estimate of the relative risk did not change (relative risk 0.65 (0.43 to 0.99)). Among current smokers only, the age adjusted relative risk for women who drank more than four glasses of alcohol a week was 0.77 (0.41 to 1.47 ), while among never smokers it was 0.38 (0.15 to 0.97$)$.

The dose-response trend estimated with restricted cubic splines showed that the risk of developing rheumatoid arthritis decreased with alcohol intake between two and four glasses a week

(figure $\Downarrow$ ). No further decrease in risk was observed with intake above four glasses a week.

Women who drank beer or liquor more than four times a month had a non-significant smaller risk of rheumatoid arthritis than never drinkers (table $3 \Downarrow$ ). Women who drank wine more than eight times a month had a non-significant $16 \%$ decreased risk compared with women who drank wine less than once a month or never drank wine.

Table $4 \Downarrow$ shows the association between long term alcohol consumption and risk of rheumatoid arthritis. The risk among those who drank more than three glasses of alcohol per week in both 1987 (at ages 39-74 years) and 1997 (at ages 49-84 years) was $52 \%$ lower compared with those who were never drinkers at both assessments.

The results of our sensitivity analyses using four additional case definitions of rheumatoid arthritis and making assumptions about inclusion of $0-20 \%$ of prevalent cases with different drinking habits were extremely similar to our overall analyses (see tables A and B of appendix on bmj.com).

\section{Discussion}

In this prospective, population based, cohort study we observed that alcohol intake was inversely associated with risk of rheumatoid arthritis. In particular, women who drank more than four glasses of alcohol (60 g ethanol) a week had a significantly lower risk of developing rheumatoid arthritis during the follow-up period. Long term alcohol intake ( $>3$ glasses a week in both 1987 and 1997) was associated with halved risk of rheumatoid arthritis. Results regarding frequency of beer, wine, and liquor consumption, though not statistically significant, supported the conclusion that moderate consumption of alcohol (ethanol) may be a protective factor for rheumatoid arthritis, since the level of reduction in risk was similar for all three types of alcoholic drink.

\section{Comparison with other studies}

Our results based on prospective data are in agreement with results from case-control studies: four showed significant inverse association between alcohol intake and rheumatoid arthritis, ${ }^{5-8}$ while one reported a non-significant inverse association. ${ }^{22}$ Two prospective cohort studies did not observe any association between alcohol intake and rheumatoid arthritis..$^{9-11}$ However, in one of these studies, on American women, no adjustment was made for smoking, which is positively correlated with alcohol intake and is a strong risk factor for rheumatoid arthritis. ${ }^{10}$ This might partly explain the discrepancy with our results. In the other study, on Finnish men and women aged 20-98, results were based only on 89 cases of seropositive rheumatoid arthritis. ${ }^{911}$ The only prospective study that analysed specific types of alcoholic drink (beer, wine, and liquor) observed a non-significant inverse association with beer (results not adjusted for smoking).$^{10}$ No study so far has analysed the association between long term alcohol intake and risk of rheumatoid arthritis.

\section{Biological mechanism}

Alcohol has been shown to down regulate immune response in animals $^{2324}$ and humans $\mathrm{s}^{25}$ and to decrease the production of selected proinflammatory cytokines in animals. ${ }^{26}$ A study on mice showed that low persistent ethanol intake from water containing $10 \%$ (vol/vol) ethanol, delays the onset and stops the progression of rheumatoid arthritis by interacting with innate immune responsiveness. ${ }^{27}$ A recent study of incident rheumatoid arthritis from the Nurses' Health Study found a U-shaped association between daily alcohol consumption and interleukin 6 levels before onset of rheumatoid arthritis, with minimum interleukin 6 levels at an alcohol intake of 10-12 g ethanol daily 
(about 1 drink a day). ${ }^{3}$ In the same study, levels of soluble tumour necrosis factor receptor 2 decreased with increasing daily alcohol intake (range 0-20 g per day). A cross sectional study of women showed that the lowest concentration of $\mathrm{C}$ reactive protein was observed in moderate drinkers $(\leq 20 \mathrm{~g}$ alcohol per day). ${ }^{28} \mathrm{~A}$ case-control study from UK reported an inverse association between alcohol consumption and all five studied markers for rheumatoid arthritis severity $(\mathrm{C}$ reactive protein, joint disease activity score, pain visual analogue scale, modified health assessment questionnaire, and modified Larsen score) in patients with established rheumatoid arthritis. ${ }^{6}$ Additionally this study showed an inverse association between alcohol consumption and radiological evidence of damage to hands and feet.

\section{Strengths and limitation}

The main strength of this study is its prospective population based design, in which the ascertainment of the alcohol exposure was independent from the ascertainment of the outcome. Therefore, this study was not affected by differential recall bias. Moreover, our cohort was well representative of the whole Swedish female population in terms of distribution of age, education, and body mass index. For this reason, it is unlikely that this study was affected by selection bias. Since data about exposures were collected in 1987 and 1997, we were able to analyse long term alcohol intake. Moreover, assessment of the exposure was done taking into account not only status of drinking, but also frequency and amount at each occasion of drinking of different alcoholic beverages (beer, wine, and liquor).

In contrast to a previous cohort study using self reported and subsequently validated diagnosis of rheumatoid arthritis, ${ }^{10}$ we used data from three Swedish registers to ascertain cases of rheumatoid arthritis. The use of the national registers, however, has some limitations. The Outpatient Register started only in 2001, and, during the first years, this register caught for the first time patients who had a diagnosis of rheumatoid arthritis before 2001. Analysis performed in our cohort showed that in 2002 the Outpatient Register identified as new rheumatoid arthritis cases 2.5 times more patients compared with the following years (see figure App-1 in appendix on bmj.com). For this reason, we decided to use year 2003 as the start of follow-up. However, we also conducted a sensitivity analysis considering 2004 and 2006 as alternative dates for start of follow-up. In the main analyses we did not use information from the Inpatient Register since the data covers hospitalisations, and rheumatoid arthritis does not typically lead to hospitalisation in its early stages. We included data from the Inpatient register in the sensitivity analyses in order to evaluate whether a less restrictive definition of incident rheumatoid arthritis might change the results. The Swedish Rheumatology Register has insufficient coverage of the study area to allow the use of this register as the only source for case identification. Results on alcohol intake from the main analysis and in all sensitivity analyses were similar.

Our study has some limitations. We could not evaluate the effect of high doses of alcohol on risk of rheumatoid arthritis because of the lack of heavy drinkers in our cohort of elderly Swedish women, who traditionally drink relatively little alcohol (only $1.4 \%$ of women in the cohort consumed more than two glasses of alcohol a day, of whom two women developed rheumatoid arthritis during follow-up). Moreover, we did not have information on family history of rheumatoid arthritis, a possible confounder of the association under study and a proxy for shared familial (genetic and environmental) factors. A possible source of non-differential misclassification of the exposure was that study participants might have underreported alcohol intake because they consider alcohol drinking as a socially undesirable behaviour. However, the high validity of alcohol intake estimates in both 1987 and 1997 indicated that the food frequency questionnaire provided a valid and reliable assessment for alcohol intake. Another possible source of misclassification may be that not all cases of prevalent rheumatoid arthritis were excluded from the study cohort. We evaluated this possibility using simulation (details in the appendix), and the results did not depart from the results obtained in the main analysis.

\section{Conclusion and clinical implications}

The results of this study indicate that moderate consumption of alcohol may reduce the risk of developing rheumatoid arthritis among women. These results are in accordance with the inverse association between moderate alcohol consumption and risk of cardiovascular disease and add to the evidence that moderate alcohol consumption is not harmful and can be protective against such a chronic disease as rheumatoid arthritis. However, the effect of higher doses of alcohol on the risk of rheumatoid arthritis remains unknown.

Contributors: All authors participated in the study design and in writing the manuscript, interpreted the data and critically reviewed the paper, and read and approved the final manuscript. DDG and AW performed the data collection. DDG analysed the data and wrote the manuscript under the supervision of AW. AW is the guarantor of the study.

Funding: The study was supported by research grants from the Swedish Research Council's Committee for Research Infrastructure for maintenance of the Swedish Mammography Cohort, and from the Karolinska Institute's Award for PhD students (KID-funding).

Competing interests: All authors have completed the ICMJE uniform disclosure form at www.icmje.org/coi_disclosure.pdf (available on request from the corresponding author) and declare: no support from any organisation for the submitted work; no financial relationships with any organisations that might have an interest in the submitted work in the previous three years, no other relationships or activities that could appear to have influenced the submitted work.

Ethical approval: This study was approved by the Regional Research Ethics Board at the Karolinska Institute, and all participants gave their informed consent.

Data sharing: No additional data available

1 Neovius M, Simard JF, Askling J. Nationwide prevalence of rheumatoid arthritis and penetration of disease-modifying drugs in Sweden. Ann Rheum Dis 2011;70:624-9. Mandrekar P, Catalano D, White B, Szabo G. Moderate alcohol intake in humans attenuates monocyte inflammatory responses: inhibition of nuclear regulatory factor kappa B and induction of interleukin 10. Alcohol Clin Exp Res 2006;30:135-9.

3 Lu B, Solomon DH, Costenbader KH, Keenan BT, Chibnik LB, Karlson EW. Alcohol consumption and markers of inflammation in women with preclinical rheumatoid arthritis. Arthritis Rheum 2010;62:3554-9.

4 Waldschmidt TJ, Cook RT, Kovacs EJ. Alcohol and inflammation and immune responses: summary of the 2005 Alcohol and Immunology Research Interest Group (AIRIG) meeting. Alcohol 2006;38:121-5.

5 Kallberg H, Jacobsen S, Bengtsson C, Pedersen M, Padyukov L, Garred P, et al. Alcohol consumption is associated with decreased risk of rheumatoid arthritis: results from two Scandinavian case-control studies. Ann Rheum Dis 2009;68:222-7.

6 Maxwell JR, Gowers IR, Moore DJ, Wilson AG. Alcohol consumption is inversely associated with risk and severity of rheumatoid arthritis. Rheumatology (Oxford) 2010;49:2140-6.

7 Hazes JM, Dijkmans BA, Vandenbroucke JP, de Vries RR, Cats A. Lifestyle and the risk of rheumatoid arthritis: cigarette smoking and alcohol consumption. Ann Rheum Dis 1990;49:980-2.

8 Pedersen M, Jacobsen S, Klarlund M, Pedersen BV, Wiik A, Wohlfahrt J, et al. Environmental risk factors differ between rheumatoid arthritis with and without auto-antibodies against cyclic citrullinated peptides. Arthritis Res Ther 2006;8:R133.

9 Heliovaara M, Aho K, Knekt P, Impivaara O, Reunanen A, Aromaa A. Coffee consumption, rheumatoid factor, and the risk of rheumatoid arthritis. Ann Rheum Dis 2000;59:631-5.

10 Cerhan JR, Saag KG, Criswell LA, Merlino LA, Mikuls TR. Blood transfusion, alcohol use, and anthropometric risk factors for rheumatoid arthritis in older women. $J$ Rheumatol 2002;29:246-54

11 Aho K, Heliovaara M. Alcohol, androgens and arthritis. Ann Rheum Dis 1993;52:897.

12 Hansson LM, Galanti MR. Diet-associated risks of disease and self-reported food consumption: how shall we treat partial nonresponse in a food frequency questionnaire? Nutr Cancer 2000;36:1-6. 


\section{What is already known on this topic}

Case-control studies have reported that drinking alcohol is associated with a lower risk of rheumatoid arthritis, but prospective cohort studies did not observe any significant association

The relation between alcohol intake and rheumatoid arthritis remains controversial

\section{What this study adds}

The present prospective study showed that women with a consistent consumption of more than three drinks a week for a period of at least 10 years had about half the risk of developing rheumatoid arthritis compared with non-drinkers

The observed inverse association seemed to be independent of the type of alcohol consumed (beer, wine, or liquor)

13 Messerer M, Johansson SE, Wolk A. The validity of questionnaire-based micronutrient intake estimates is increased by including dietary supplement use in Swedish men. J Nutr 2004;134:1800-5.

14 Friberg E, Wolk A. Long-term alcohol consumption and risk of endometrial cancer incidence: a prospective cohort study. Cancer Epidemiol Biomarkers Prev 2009;18:355-8.

15 Baecklund E, lliadou A, Askling J, Ekbom A, Backlin C, Granath F, et al. Association of chronic inflammation, not its treatment, with increased lymphoma risk in rheumatoid arthritis. Arthritis Rheum 2006;54:692-701.

16 Knight A, Sandin S, Askling J. Increased risk of autoimmune disease in families with Wegener's granulomatosis. J Rheumatol 2010;37:2553-8.

17 Ludvigsson JF, Otterblad-Olausson P, Pettersson BU, Ekbom A. The Swedish personal identity number: possibilities and pitfalls in healthcare and medical research. Eur $\mathrm{J}$ Epidemiol 2009;24:659-67.

18 Korn EL, Graubard BI, Midthune D. Time-to-event analysis of longitudinal follow-up of a survey: choice of the time-scale. Am J Epidemiol 1997;145:72-80.

19 Thiebaut AC, Benichou J. Choice of time-scale in Cox's model analysis of epidemiologic cohort data: a simulation study. Stat Med 2004;23:3803-20.

20 Schoenfeld D. Partial residuals for the proportional hazards regression model. Biometrika 1982;69:239-41.

21 Harrell FE Jr, Lee KL, Pollock BG. Regression models in clinical studies: determining relationships between predictors and response. J Natl Cancer Inst 1988;80:1198-202.

22 Voigt LF, Koepsell TD, Nelson JL, Dugowson CE, Daling JR. Smoking, obesity, alcohol consumption, and the risk of rheumatoid arthritis. Epidemiology 1994;5:525-32.

23 Verma S, Alexander CM, Carlson MJ, Tygrett LT, Waldschmidt TJ. B-cell studies in chronic ethanol mice. Methods Mol Biol 2008;447:295-323.
24 Fan J, Edsen-Moore MR, Turner LE, Cook RT, Legge KL, Waldschmidt TJ, et al. Mechanisms by which chronic ethanol feeding limits the ability of dendritic cells to stimulate T-cell proliferation. Alcohol Clin Exp Res 2011;35:47-59.

25 Mandrekar P, Catalano D, Dolganiuc A, Kodys K, Szabo G. Inhibition of myeloid dendritic cell accessory cell function and induction of $\mathrm{T}$ cell anergy by alcohol correlates with decreased IL-12 production. J Immunol 2004:173:3398-407.

26 Waldschmidt TJ, Cook RT, Kovacs EJ. Alcohol and inflammation and immune responses: summary of the 2005 Alcohol and Immunology Research Interest Group (AIRIG) meeting. Alcohol 2006;38:121-5.

27 Jonsson IM, Verdrengh M, Brisslert M, Lindblad S, Bokarewa M, Islander U, et al. Ethanol prevents development of destructive arthritis. Proc Nat Acad Sci U S A 2007;104:258-63.

28 Imhof A, Woodward M, Doering A, Helbecque N, Loewel H, Amouyel P, et al. Overall alcohol intake, beer, wine, and systemic markers of inflammation in western Europe: results from three MONICA samples (Augsburg, Glasgow, Lille). Eur Heart $J$ 2004;25:2092-100

\section{Accepted: 15 May 2012}

\section{Cite this as: BMJ 2012;345:e4230}

This is an open-access article distributed under the terms of the Creative Commons Attribution Non-commercial License, which permits use, distribution, and reproduction in any medium, provided the original work is properly cited, the use is non commercial and is otherwise in compliance with the license. See: http://creativecommons.org/licenses/bync/2.0/ and http://creativecommons.org/licenses/by-nc/2.0/legalcode. 


\section{Tables}

Table 1| Baseline characteristics of 34141 women in the Swedish Mammography Cohort in 1997 by alcohol status and number of glasses of alcohol consumed per week

\begin{tabular}{|c|c|c|c|c|c|c|c|c|}
\hline \multirow[b]{2}{*}{ Characteristic } & \multicolumn{4}{|c|}{ Alcohol status } & \multicolumn{4}{|c|}{ No of glasses of alcohol/week } \\
\hline & $\begin{array}{c}\text { Never } \\
(n=4290)\end{array}$ & $\begin{array}{l}\text { Former } \\
(n=1340)\end{array}$ & $\begin{array}{c}\text { Occasional } \\
\text { drinkers } \\
(n=16733)^{*}\end{array}$ & $\begin{array}{l}\text { Regular drinkers } \\
\quad(n=11 \text { 778) } \dagger\end{array}$ & $\begin{array}{l}<1 \text { or never } \\
(n=12488)\end{array}$ & $1-2(n=5319)$ & $>2-4(n=6508)$ & $>4(n=7497)$ \\
\hline $\begin{array}{l}\text { Mean (SD) age } \\
\text { (years) }\end{array}$ & $67.3(8.8)$ & $64.7(9.4)$ & $61.3(8.9)$ & $58.8(8.1)$ & $64.2(9.2)$ & $61(8.8)$ & $59(8.1)$ & $57.7(7.5)$ \\
\hline No (\%) nulliparous & $499(11.9)$ & $153(11.6)$ & $1483(9)$ & $1045(8.9)$ & $1249(10.3)$ & $464(8.8)$ & $577(8.9)$ & $637(8.6)$ \\
\hline $\begin{array}{l}\text { No (\%) current } \\
\text { smokers }\end{array}$ & $342(8.1)$ & $334(25.6)$ & $3876(24.5)$ & $3178(27.5)$ & $2008(16.4)$ & $1195(22.9)$ & $1605(25)$ & $2350(31.7)$ \\
\hline \multicolumn{9}{|l|}{$\begin{array}{l}\text { Mean (SD) alcohol } \\
\text { intake (No of } \\
\text { glasses/month): }\end{array}$} \\
\hline Beer & - & - & $1.1(1.2)$ & $6.3(8.2)$ & $0.7(2.2)$ & $2.1(4.1)$ & $3.3(4.5)$ & $6.4(8.3)$ \\
\hline Wine & - & - & $1.6(1.3)$ & $7.6(7.7)$ & $0.7(1.3)$ & $2.2(2)$ & $4.1(2.8)$ & $8.8(8.4)$ \\
\hline Liquor & - & - & $0.5(0.7)$ & $2.1(4.1)$ & $0.2(0.9)$ & $0.6(1.2)$ & $1.1(1.8)$ & $2.6(4.3)$ \\
\hline
\end{tabular}

*Occasional drinkers $\leq 2$ glasses of alcohol/week.

†Regular drinkers $>2$ glasses of alcohol/week. 
Table 2/ Relative risk of rheumatoid arthritis during follow-up (2003-09) of women in the Swedish Mammography Cohort by alcohol status in 1997 and number of glasses of alcohol consumed per week

Relative risk $(95 \% \mathrm{Cl})$

\begin{tabular}{|c|c|c|c|c|}
\hline & \multirow[b]{2}{*}{ No of cases of arthritis ${ }^{*}$} & \multirow[b]{2}{*}{ No of person years } & \multicolumn{2}{|c|}{ Relative risk (95\% Cl) } \\
\hline & & & Adjusted for age & Adjusted for age and smoking $\dagger$ \\
\hline \multicolumn{5}{|l|}{ Alcohol status } \\
\hline Never & 21 & 27063 & $0.91(0.56$ to 1.46$)$ & $1.09(0.67$ to 1.80$)$ \\
\hline Former & 6 & 8559 & $0.79(0.35$ to 1.80$)$ & $0.80(0.35$ to 1.84$)$ \\
\hline Occasional drinkers $\ddagger$ & 105 & 111067 & 1.00 & 1.00 \\
\hline Regular drinkers§ & 65 & 79343 & $0.85(0.62$ to 1.15$)$ & $0.81(0.59$ to 1.11$)$ \\
\hline \multicolumn{5}{|c|}{ No of glasses of alcohol/week } \\
\hline$<1$ or never & 73 & 81087 & 1.00 & 1.00 \\
\hline $1-2$ & 30 & 35439 & $0.89(0.58$ to 1.36$)$ & 0.86 (0.56 to 1.33$)$ \\
\hline$>2-4$ & 45 & 43947 & $1.05(0.72$ to 1.53$)$ & 0.99 (0.67 to 1.46$)$ \\
\hline$>4 \uparrow$ & 37 & 50798 & $0.74(0.49$ to 1.11$)$ & $0.63(0.42$ to 0.96$)$ \\
\hline$P$ value for trend & - & - & 0.17 & 0.04 \\
\hline
\end{tabular}

*Number of cases do not add to total $(n=197)$ due to missing values on information about amount of drinking and missing values for former drinkers. †Adjusted for age (continuous) and smoking status (never, former, current $\leq 10$ cigarettes/day, or $>10$ cigarettes/day). Further adjustment for body mass index, educational level, parity, menopausal status, and consumption of meat and dairy products did not change the estimates.

Occasional drinkers: 2 or less drinks per week; Regular drinkers: more than 2 drinks per week.

$\ddagger$ Occasional drinkers $\leq 2$ glasses of alcohol/week.

$\S$ Regular drinkers $>2$ glasses of alcohol/week.

†Median of 6 glasses/week. 
Table 3| Relative risk of rheumatoid arthritis during follow-up (2003-09) of women in the Swedish Mammography Cohort by frequency of drinking of beer, wine, and liquor in 1997

\begin{tabular}{|c|c|c|c|c|}
\hline \multirow[b]{2}{*}{ Alcohol type } & \multirow{2}{*}{$\begin{array}{c}\text { No of cases of } \\
\text { arthritis* }\end{array}$} & \multirow[b]{2}{*}{ No of person years } & \multicolumn{2}{|c|}{ Relative risk $(95 \% \mathrm{Cl})$} \\
\hline & & & Adjusted for age & Adjusted for age and smoking \\
\hline \multicolumn{5}{|c|}{ Beer (No of glasses/month) } \\
\hline Never & 80 & 89589 & 1.00 & 1.00 \\
\hline$<1$ & 48 & 50498 & $0.99(0.68$ to 1.44$)$ & $0.91(0.62$ to 1.34$)$ \\
\hline $1-4$ & 30 & 36242 & $0.86(0.56$ to 1.34$)$ & $0.85(0.55$ to 1.32$)$ \\
\hline$>4 \ddagger$ & 33 & 41144 & $0.85(0.55$ to 1.31$)$ & $0.84(0.54$ to 1.30$)$ \\
\hline$\underline{P}$ value for trend & 一 & - & 0.43 & 0.43 \\
\hline \multicolumn{5}{|c|}{ Wine (No of glasses/month) } \\
\hline$<1$ & 74 & 84574 & 1.00 & 1.00 \\
\hline $1-4$ & 63 & 70797 & $0.98(0.68$ to 1.40$)$ & $0.97(0.68$ to 1.40$)$ \\
\hline $5-8$ & 38 & 42278 & $0.99(0.65$ to 1.52$)$ & $0.96(0.62$ to 1.47$)$ \\
\hline$>8 \ddagger$ & 16 & 19824 & $0.91(0.51$ to 1.63$)$ & $0.84(0.47$ to 1.52$)$ \\
\hline$P$ value for trend & - & - & 0.83 & 0.55 \\
\hline \multicolumn{5}{|c|}{ Liquor (No of glasses/month) } \\
\hline Never & 93 & 107630 & 1.00 & 1.00 \\
\hline$<1$ & 67 & 72588 & $1.06(0.75$ to 1.49$)$ & $0.93(0.66$ to 1.32$)$ \\
\hline $1-4$ & 22 & 25571 & $1.02(0.62$ to 1.67$)$ & $0.85(0.51$ to 1.41$)$ \\
\hline$>4 \ddagger$ & 9 & 11683 & $0.92(0.45$ to 1.90$)$ & $0.77(0.37$ to 1.59$)$ \\
\hline$P$ value for trend & - & - & 0.81 & 0.43 \\
\hline
\end{tabular}

*Any cases with missing values for frequency of alcohol intake were assumed to mean never consumption.

†Adjusted for age (continuous) and smoking status (never, former, current $\leq 10$ cigarettes/day, or $>10$ cigarettes/day). Further adjustment for body mass index, educational level, parity, menopausal status, and consumption of meat and dairy products did not change the estimates.

$\ddagger$ Median values in the highest categories were 7 /month for beer, 15/month for wine, and 6.5/month for liquor. 
Table 4| Multivariable adjusted relative risk* of rheumatoid arthritis during follow-up (2003-09) of women in the Swedish Mammography Cohort by weekly alcohol intake in 1987 and 1997

\begin{tabular}{|c|c|c|c|c|c|c|}
\hline \multirow{3}{*}{$\begin{array}{c}\text { Alcohol intake } \\
1987\end{array}$} & \multicolumn{6}{|c|}{ Alcohol intake 1997} \\
\hline & \multicolumn{2}{|c|}{ Never drinkers } & \multicolumn{2}{|c|}{$\leq 3$ glasses/week } & \multicolumn{2}{|c|}{$>3$ glasses/week } \\
\hline & No of cases & Relative risk $(95 \% \mathrm{Cl})$ & No of cases & Relative risk $(95 \% \mathrm{Cl})$ & No of cases & Relative risk $(95 \% \mathrm{Cl})$ \\
\hline Never & 21 & 1.00 (reference) & 28 & $0.96(0.54$ to 1.73$)$ & 1 & $0.43(0.06$ to 3.20$)$ \\
\hline$\leq 3$ glasses/week & - & - & 76 & $0.78(0.47$ to 1.30$)$ & 38 & $0.61(0.34$ to 1.09$)$ \\
\hline$>3$ glasses/week & - & - & 7 & 1.34 (0.56 to 3.22$)$ & 14 & $0.48(0.24$ to 0.98$)$ \\
\hline
\end{tabular}

*Adjusted for age (continuous) and smoking status (categorised as never, former, current $\leq 10$ cigarettes/day, or $>10$ cigarettes/day). 


\section{Figure}

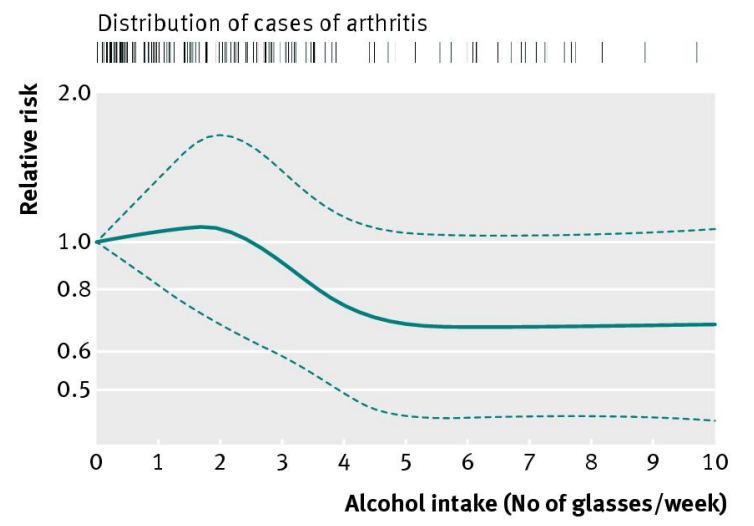

Fig 1 Dose-response relative risk (with 95\% confidence interval) of rheumatoid arthritis by alcohol consumption (glasses of alcohol/week). Model was adjusted for age (continuous), parity (quartiles), and smoking status (never, former, current $\leq 10$ cigarettes/day, or $>10$ cigarettes/day). Tick marks represent distribution of cases according to alcohol intake 